\title{
Does negative plus negative give positive? The value of combining intradiscal treatment strategies
}

\author{
Claudius Thomé $\cdot$ Bernhard Meyer
}

Received: 17 June 2010 / Accepted: 18 June 2010 / Published online: 14 July 2010

(C) Springer-Verlag 2010

Keywords Medicine $\cdot$ Spine surgery

Combining different treatment strategies is common practice in medical therapy by pharmaceutical agents. Why not do the same in spine surgery?

Obviously, any combination of treatments requires rigorous analysis of possible synergistic or antagonistic effects on outcome. Ahn and Lee provide a well-designed prospective study on the combination of percutaneous endoscopic lumbar discectomy with thermal annuloplasty for mono- or bisegmental discogenic low back pain. Outcome assessment is based on widely accepted scales, and a follow-up rate of $90 \%$ after 2 years is generally considered sufficient for evaluation in spine surgery. The success rate of $70 \%$ suggests a considerable value of the proposed combination for discogenic low back pain, although it has dropped from $90 \%$ reported in a preceding series of 30 patients presented by the same group in 2009 [4].

Does the combination of two minimally invasive techniques finally offer a surgical solution for discogenic low back pain? We doubt it!

The concept of combining a "thermal annuloplasty effect" and a "decompression effect" is not new and has been used since the late 1990s [9]. Intradiscal electrother-

\section{Thomé $(\bowtie)$}

Department of Neurosurgery, Medical University Innsbruck,

Anichstr. 35,

6020 Innsbruck, Austria

e-mail: claudius.thome@uki.at

\section{B. Meyer}

Department of Neurosurgery, Technical University Munich,

Klinikum Rechts der Isar, Ismaninger Str. 22,

81675 Munich, Germany

e-mail: bernhard.meyer@1rz.tum.de mal therapy (IDET) has been based on the mechanisms of action proposed by the authors and has also started out with a success rate of $70 \%$ [8]. Randomised controlled trials, however, demonstrated that IDET is no better than placebo in the treatment of discogenic low back pain $[3,6]$. The selective citation of annuloplasty results as provided in the paper is not scientifically sound. There is no evidence for percutaneous mechanical disc decompression in managing axial low back pain [5]. Thus, both intradiscal decompression and annuloplasty have not demonstrated long-term efficacy according to the pertinent literature. Can we expect that the combination of two ineffective or at least questionable treatment strategies will be effective in the treatment of discogenic low back pain? Does negative plus negative give positive? It cannot be stressed enough that the presented data are not based on a randomised and not even a controlled study. An independent observer does not at all eliminate bias if there is no control group, and telephone interviews as part of the postoperative assessment give limited information. Thus, without further data derived from randomised controlled trials, there is no indication that the proposed treatment works better than standardised conservative care.

The authors put great emphasis on the technical aspects of their percutaneous technique: elimination of "inflamed" nucleus tissue, preservation of normal nucleus, thermal modulation along the whole length of the posterior annulus, and so on. However, these considerations are based on unproven assumptions and theoretical pathophysiological speculations. One third of treated segments were classified as Pfirrmann grade 4, in which differentiation of nucleus and annulus is lost by definition [7]. These patients obviously do not have a normal nucleus.

What we, however, dislike most about the proposed technique is its destructive nature. Discectomy, be it by open 
surgery or endoscopy, is known to accelerate disc degeneration $[1,10]$ and cause secondary low back pain, particularly at long-term follow-up. When even puncturing a disc for discography has dramatic detrimental effects [2], how can we even pretend to save the "innocent central" nucleus in the degenerated discs we operate? The authors damage the disc by (1) puncture, (2) endoscopic forceps, (3) laser and (4) bipolar radiofrequency annuloplasty. Obviously, there are no more destructive techniques that could be combined to destroy the disc! Although the involved mechanisms are not yet clear, many investigators and spine surgeons nowadays absolutely minimise damage to the disc. Intradiscal therapies destroy the disc mechanically and thermally regardless of their percutaneous minimal invasive nature, and we are convinced that this will worsen long-term prognosis. With this combination of techniques being around for more than a decade, it simply cannot be advocated without randomised controlled trials as provided for IDET and without long-term evaluation of intradiscal sequelae.

The authors have to be congratulated for trying to identify a subpopulation of patients most suitable for their technique as proper patient selection is crucial for outcome of spine surgery. It is noteworthy that the presence of disc herniation was the most significant predictor of outcome with an odds ratio of more than 3! Obviously, patients with disc herniations that were removed during the procedure fared best. Did the authors evaluate a treatment strategy for disc herniations, which additionally involves destruction of significant portions of the disc by forceps plus laser plus radiofrequency rather than identifying a successful treatment for discogenic low back pain?

We are sticking with mathematics - negative plus negative still gives negative!

\section{References}

1. Barth M, Diepers M, Weiss C, Thomé C (2008) Two-year outcome after lumbar microdiscectomy versus microscopic sequestrectomy: part 2: radiographic evaluation and correlation with clinical outcome. Spine 33:273-279

2. Carragee EJ, Don AS, Hurwitz EL, Cuellar JM, Carrino J, Herzog R (2009) 2009 ISSLS Prize Winner: Does discography cause accelerated progression of degeneration changes in the lumbar disc: a ten-year matched cohort study. Spine 34:2338-2345

3. Freeman BJ, Fraser RD, Cain CM, Hall DJ, Chapple DC (2005) A randomized, double-blind, controlled trial: intradiscal electrothermal therapy versus placebo for the treatment of chronic discogenic low back pain. Spine 30:2369-2377

4. Lee SH, Kang HS (2010) Percutaneous endoscopic laser annuloplasty for discogenic low back pain. Surg Neurol 73:198206

5. Manchikanti L, Derby R, Benyamin RM, Helm S, Hirsch JA (2009) A systematic review of mechanical lumbar disc decompression with nucleoplasty. Pain Physician 12:561-572

6. Pauza KJ, Howell S, Dreyfuss P, Peloza JH, Dawson K, Bogduk N (2004) A randomized, placebo-controlled trial of intradiscal electrothermal therapy for the treatment of discogenic low back pain. Spine J 4:27-35

7. Pfirrmann CW, Metzdorf A, Zanetti M, Hodler J, Boos N (2001) Magnetic resonance classification of lumbar intervertebral disc degeneration. Spine 26:1873-1878

8. Saal JA, Saal JS (2000) Intradiscal electrothermal treatment for chronic discogenic low back pain: a prospective outcome study with minimum 1-year follow-up. Spine 25:2622-2627

9. Tsou PM, Alan Yeung C, Yeung AT (2004) Posterolateral transforaminal selective endoscopic discectomy and thermal annuloplasty for chronic lumbar discogenic pain: a minimal access visualized intradiscal surgical procedure. Spine J 4:564573

10. Yorimitsu E, Chiba K, Toyama Y, Hirabayashi K (2001) Long-term outcomes of standard discectomy for lumbar disc herniation: a follow-up study of more than 10 years. Spine $26: 652-657$ 